\title{
Giant bladder stone: A case report and review of the literature
}

\author{
İbrahim Nüvit Tahtalı ${ }^{1}$ Turgay Karataş²
}

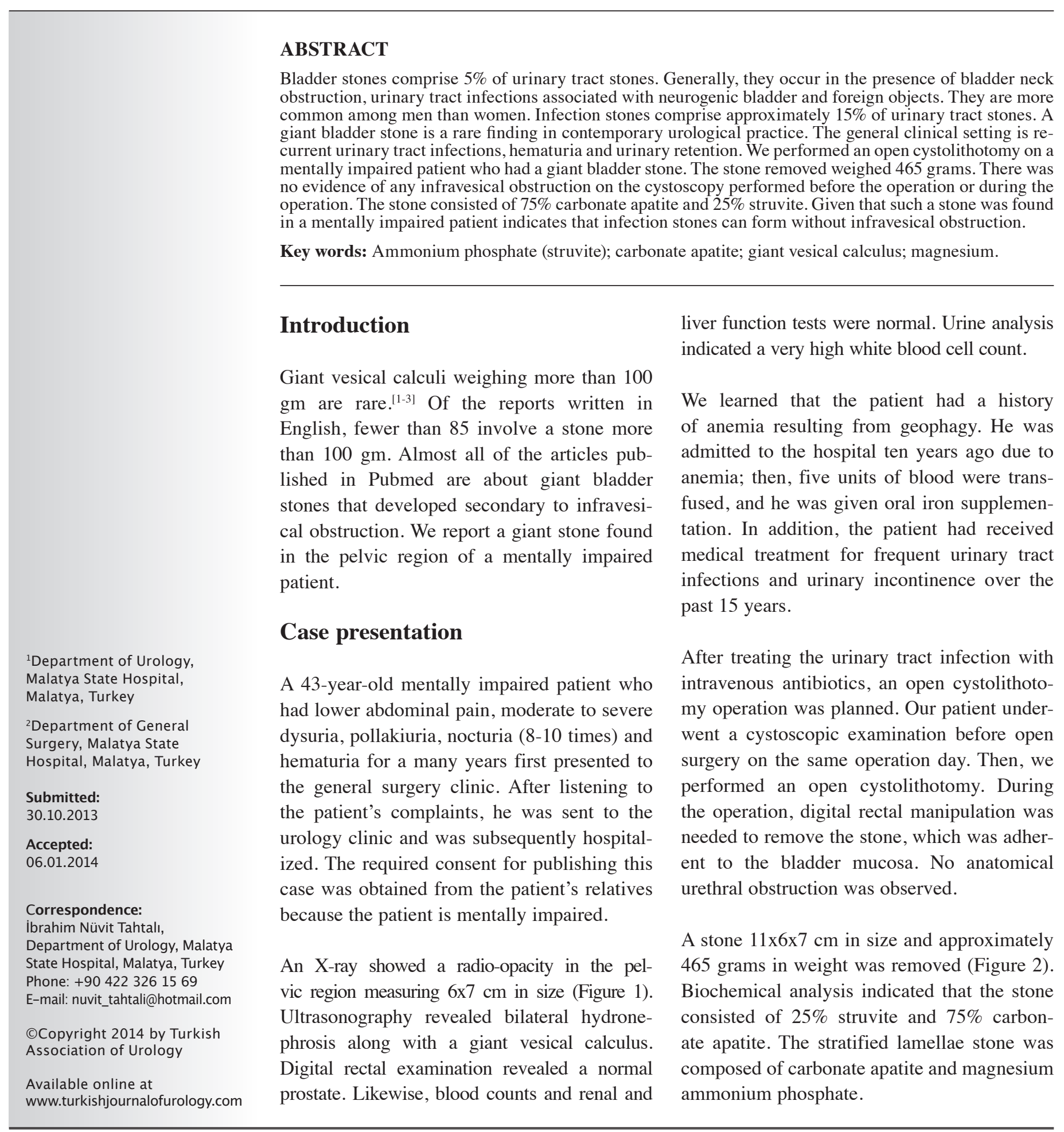




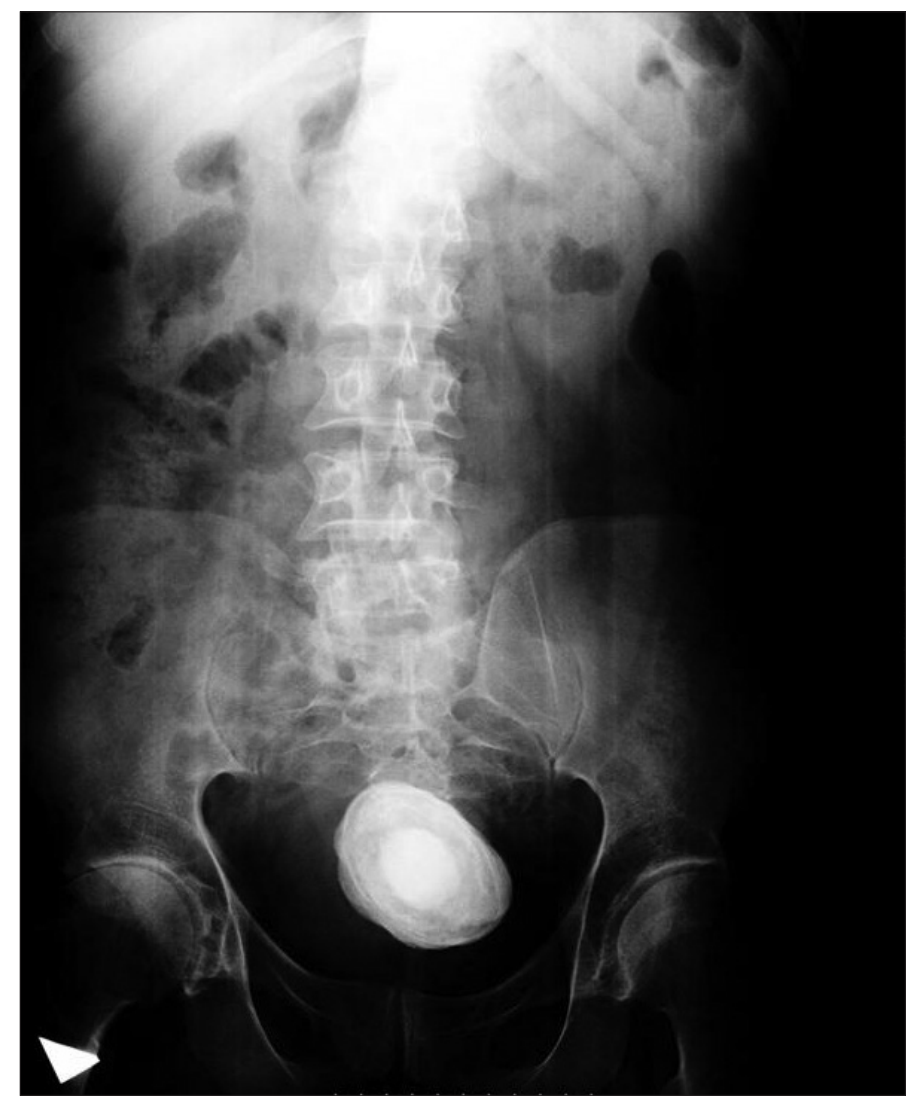

Figure 1. Large pelvic stone in direct ultrasonography

The post-operative period was uneventful. The urethral catheter was removed on the $8^{\text {th }}$ postoperative day, and the patient's urinary output was normal. The patient was discharged on postoperative day 8 . The patient was voiding normally, despite complaining of mild lower urinary tract symptoms (LUTS), mostly irritative, and the bilateral hydronephrosis improved markedly within 3 weeks.

\section{Discussion}

Epidemiological surveys of urolithiasis have shown a prevalence between 4 and $20 \%$ in developed countries. ${ }^{[4,5]}$ Mostly resulting from bladder outlet obstruction, neurogenic voiding dysfunction, urinary tract infection or foreign bodies, bladder calculi account for $5 \%$ of urinary calculi. ${ }^{[1,3]}$ Children remain at high risk for bladder stone development in endemic areas. ${ }^{[6]}$ In non-endemic regions, bladder calculi are often found in adults. Females are less affected than males. ${ }^{[1,4,6]}$ Recurrent urinary tract infection, hematuria and urinary retention are common disorders in these patients..$^{[1,3]}$ Nevertheless, in endemic areas, in children in whom a major anatomic abnormality does not coexist, bladder calculi can occur; in these regions, the primary influential factors are dietary intake and socio-economic factors leading to the formation of bladder calculi. ${ }^{[7,8]}$

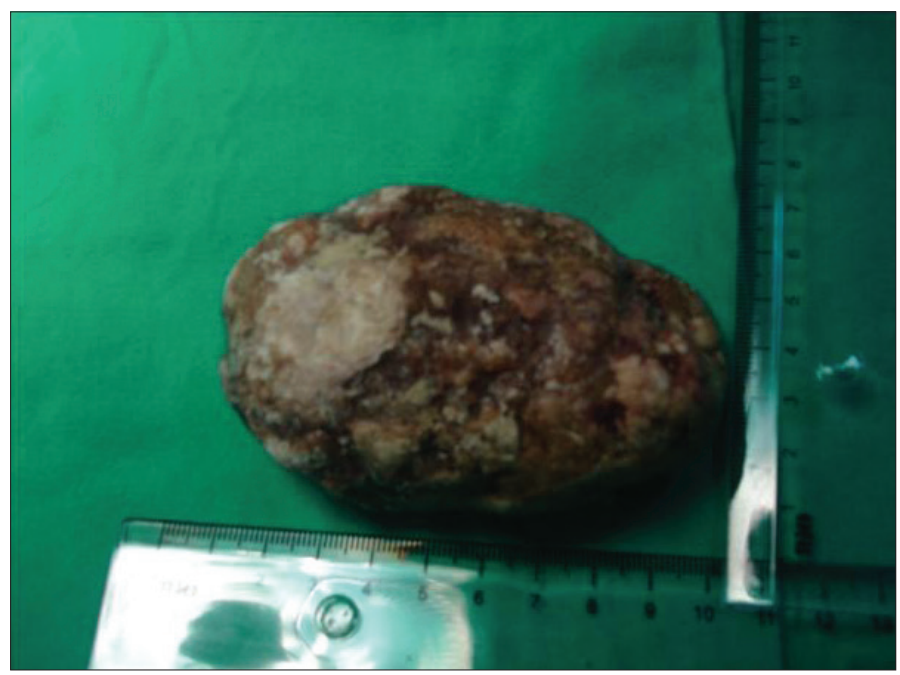

Figure $2.11 \times 7 \times 6 \mathrm{~cm}$ bladder stone was extracted by open cystolithotomy

Bladder stones are mostly associated with renal or ureteral calculi, and they rarely ever occur without associated upper urinary tract calculi, as in our patient. ${ }^{[1]}$ Primary vesical calculosis is quite commonplace in Asia, with calculi consisting of ammonium urate and calcium oxalate. Because of malnutrition in the very early years of life, vesical calculosis is now common in Turkey, Iran, India, China, and Indonesia; however, there is a decrease in the incidence as social conditions gradually improve. [5]

Infected stones make up approximately $15 \%$ of urinary stone diseases and are thus an important group. ${ }^{[5,9]}$ These stones are composed of struvite and/or carbonate apatite. The basic precondition for the formation of infected stones is a ureasepositive urinary tract infection. As a result, ammonium ions can form, and at the same time, alkaline urine develops. Both are preconditions for the formation of struvite and carbonate apatite crystals. When these crystals deposit, infected stones form. ${ }^{[9]}$

The preferred method for diagnosis is cystoscopy, but an X-ray or an ultrasound is sometimes enough. Because of its size, cystolithotomy is the correct treatment for a giant bladder stone..$^{[1,3,6]}$

There are a number of techniques and modalities available to remove bladder stones. Relieving the obstruction, eliminating the infection, meticulous surgical technique, and accurate diagnosis are essential in their treatment. ${ }^{[6,10]}$

In recent urological practice, a giant bladder calculus is rare, especially those greater than 100 grams. ${ }^{[1,2]}$ When searching Pubmed for articles on this topic in the last 30 years, less than 85 relevant articles were found. 
Our aim in this report is to show that this rare clinical presentation is able to develop in the absence of infravesical obstruction.

In conclusion, almost all reports of giant bladder stones published so far are stones that formed secondary to preoperative situations, such as infravesical obstruction, neurogenic bladder or foreign bodies. We think that this case is striking because of the finding that a giant infected stone can develop in the bladder without any predisposing cause, warranting further investigation.

As a second finding after reviewing the related literature on this topic, we believe that large bladder stones should be viewed as a different clinical presentation than small bladder stones, especially regarding the cause of their formation and treatment option. We propose that this topic needs further discussion and evaluation.

Informed Consent: Written informed consent was obtained from patient who participated in this case.

Peer-review: Externally peer-reviewed.

Author Contributions: Concept - İ.N.T.; Design - İ.N.T., T.K.; Funding - İ.N.T.; Analysis and/or Interpretation - İ.N.T.; Literature Review - İ.N.T., T.K.; Writer - İ.N.T.; Critical Review - T.K.

Acknowledgements: We sincerely thank for interpretations, Assistant Professor Turan Yıldız, Sakarya University in Medical School, Departmant of Pediatric Surgery Sakarya, Turkey.
Conflict of Interest: No conflict of interest was declared by the authors.

Financial Disclosure: The authors declared that this study has received no financial support.

\section{References}

1. Aydogdu O, Telli O, Burgu B, Beduk Y. Infravesical obstruction results as giant bladder calculi. Can Urol Asoc J 2011;5:77-8.

2. Thakur RS, Minhas SS, Jhobta R, Sharma D. Giant vesical calculus presenting with azotaemia and anuria. Indian J Surg 2007;69:147-9.

3. Hizlı F, Y1lmaz E. A giant bladder struvite stone in an adolescent boy. Urol Res 2012;40:273-4.

4. Trinchieri A. Epidemiology of urolithiasis: an update. Clin Cases Miner Bone Metab 2008;5:101-6.

5. Trinchieri A. Epidemiology of urolithiasis. Arch Ital Urol Androl 1996;68:203-49.

6. Schwartz BF, Stoller ML. The vesical calculus. Urol Clin Nort Am 2000;27:333-46.

7. Ali SH, Rifat UN. Etiological and clinical patterns of childhood urolithiasis in Iraq. Pediatr Nephrol 2005;20:1453-7.

8. Douenias R, Rich M, Badlani G, Mazor D, Smith A. Predisposing factors in bladder calculi: Review of 100 cases. Urology 1991;37:240-3.

9. Bichler KH, Eipper E, Naber K. Infection-induced urinary Stones. Urologe A 2003;42:47-55.

10. Saito S, Izumitani M, Shiroki R, Ishiguro K, Nagakubo I. Prolonged exposure to intravesical foreing body induces a giant calculus with attendant renal dysfunction. Nihon Hinyokika Gakkai Zasshi 1994;85:1777-80 